\title{
Calotropis gigantea Flower Extract Induced Biomimetic Synthesis of Silver and Gold Nanoparticles and Its Application in Textile
}

\author{
S.P. Kamala Nalini ${ }^{1, *}$, K. Vijayaraghavan ${ }^{2}$ \\ ${ }^{1}$ Department of Plant Biology \& Plant Biotechnology, Sir Theagaraya College, Washermanpet, Chennai - 600021 , Tamil Nadu, India. \\ 2Department of Biotechnology, Hindustan Institute of Technology and Science, Hindustan University, Padur, Chennai - 603 103, Tamil Nadu, India.
}

\section{ART ICLEDETAILS}

\section{Article history:}

Received 27 March 2020

Accepted 17 April 2020

Available online 02 May 2020

\section{Keywords:}

Calotropis gigantea

Antimicrobial Effect

Cotton Fabric

\begin{abstract}
A B S T R A C T
A novel method of silver and gold nanoparticles were synthesized using aqueous extract of Calotropis gigantea flower. The ingredients of Calotropis gigantea were found to be glycosides, fatty acids and calcium oxalate which served as a reducing and stabilizing agent in the synthesis of nanoparticles. The experiments were conducted at a constant temperature of $32 \pm 2{ }^{\circ} \mathrm{C}$. The surface plasmon resonance band of silver and gold nanoparticles occurred at 430 and $545 \mathrm{~nm}$ respectively. The investigation proved that the formation of silver and gold nanoparticles started within $7 \mathrm{~min}$ and the reaction was completed at end of $8 \mathrm{~h}$. The characterization of the formed nanoparticles was performed using transmission electron microscope, X-ray diffraction and zeta potential studies. The spherical shaped silver and gold nanoparticles had size ranging between 8 to $17 \mathrm{~nm}$ and 9 to $20 \mathrm{~nm}$ respectively. The effectiveness of cotton fabric impregnated with silver and gold nanoparticles were tested against Escherichia coli and Staphylococcus aureus.
\end{abstract}

\section{Introduction}

Even though modern nanoscience and nanotechnology are quite new, nanoscale materials were used for centuries. The nanoscale takes to its advantage the enhanced properties due to their tunable physicochemical characteristics such as melting point, wettability, electrical and thermal conductivity modified reactivity but also the optical characteristics with respect to transparency, absorption, luminescence, scattering and greater chemical reactivity than their larger-scale counterparts. Nanomaterials can be produced by mechanical, physical, chemical and biological methods. The biological synthesis of nanoparticle had been achieved using microbes, enzymes and extracts from plant parts. The plant-mediated biosynthesis of nanoparticles has been effective to chemical and physical methods due to environmental benign approach. Nanomaterials finds numerous applications in the field of medicine as they are deployed as targeted drug delivery, antibacterial agent, sunscreens, medical textiles, imaging, sensing, gene delivery systems and artificial implants [1-4].

Plant based biosynthesis of silver and gold nanoparticles had been attempted using various plant extracts of Calotropis procera [5], leaf of Litchi chinensis [6], Euphorbia antiquorum L. latex extract [7], Calotropis gigantean leaf [8] and Calotropis gigantean flowers [9,10]. In the present investigation biometric one pot synthesis of nanoparticles has been attempted using aqueous extract of Calotropis gigantean flowers.

\section{Experimental Methods}

\subsection{Preparation of Extract from Calotropis gigantea Flowers}

Fresh flowers of Calotropis gigantea weighing about $50 \pm 0.5 \mathrm{~g}$ is grounded using mortar and pestle and extracted with $100 \mathrm{~mL}$ distilled water. The extract was filtered using Whatman filter paper 40, the filtrate served as the reducing and stabilizing agent for the synthesis of silver and gold nanoparticles.

2.2 Biosynthesis of silver and gold nanoparticles using Calotropis gigantea flowers

Nanoparticles of silver and gold were synthesized by adding $50 \mathrm{~mL}$ of aqueous extract of Calotropis gigantea flower to $10.5 \mathrm{~mL}$ of $1 \mathrm{mM}$ silver nitrate $\left(\mathrm{AgNO}_{3}\right)$ and hydrogen tetrachloroaurate $\left(\mathrm{HAuCl}_{4}\right)$ respectively. The reactions were carried out under following conditions namely $32 \pm 2$ ${ }^{\circ} \mathrm{C}, \mathrm{pH} 6.9 \pm 0.2$ and $240 \mathrm{rpm}$ respectively. During the formation of silver nanoparticles, $\mathrm{Ag}^{+}$was reduced to $\mathrm{Ag}^{0}$ which was confirmed by the change of colour from colourless to pale yellow and then to deep red brown. Whereas the reduction of $\mathrm{Au}^{3+}$ to $\mathrm{Au}^{0}$ was monitored by observing change in colour from pale yellow to red and deep blood red.

\subsection{Characterization Techniques for Nanoparticles}

The formation of nanoparticles (silver and gold) were confirmed by visual observation and subsequently based on surface plasmon resonance (SPR) which was measured using UV-VIS spectrophotometer. The size and crystalline nature was measured using transmission electron microscope, $\mathrm{X}$-ray diffraction pattern and zeta potential.

\subsection{Evaluation of Antibacterial Activity by Well Diffusion Method}

The antimicrobial effect of silver and gold nanoparticles was determined by well diffusion method against Escherichia coli and Staphylococcus aureus. The wells were filled with solution of silver and gold NPs independently at varying concentration viz: 10, 20, 30 and $40 \mu \mathrm{L}$ and incubated for $24 \mathrm{~h}$ at $35^{\circ} \mathrm{C}$ and the zone of inhibition was observed and measured after $24 \mathrm{~h}$.

\subsection{Antimicrobial Property of Silver and Gold Nanoparticles Impregnated on Cotton Fabric}

The fabric was desized with citric acid and treated with sodium lauryl sulphate for the removal of soap solution. The fabrics were immersed in AgNPs and AuNPs separately and were initially air dried and later cured at $140^{\circ} \mathrm{C}$. Escherichia coli and Staphylococcus aureus were evaluated by the parallel streak method by observing and measuring the bacterial growth underneath and around the nanoparticles impregnated cloth.

\section{Result and Discussion}

\subsection{Characterization Silver and Gold Nanoparticles}

The formation of silver and gold nanoparticles was confirmed by visual observation and subsequently verified based on the surface plasmon resonance with UV-VIS spectrophotometer over the entire reaction period. The maximum absorbance occurred at a wavelength of 430 and 
$545 \mathrm{~nm}$ for silver and gold nanoparticles when reduced with aqueous extracts of Calotropis gigantea flower. The main ingredients of Calotropis gigantea extract were found to be cardiac glycosides, fatty acids and calcium oxalate which served as a reducing and stabilizing agent. During the reduction of silver with Calotropis gigantea flower extract, the colourless $\mathrm{AgNO}_{3}$ solution changed to pale yellow and then to deep red brown as the reaction period extended up to $8 \mathrm{~h}$. In the case of gold nanoparticles synthesis with Calotropis gigantea the colour of $\mathrm{HAuCl}_{4}$ changed from pale yellow to red and then deep blood red with the increase in reaction time up to $8 \mathrm{~h}$. With the further increase in reaction time a marginal rise in intensity was observed. On completion of nanoparticles synthesis $5 \mathrm{~mL}$ of Calotropis gigantea extract was added as a stabilizing agent in order to prevent aggregation of formed nanoparticle. The colour change during the reaction period might be due to the excitation of surface plasmon resonance (SPR) of the formed nanoparticles. The SRP peak confirmed the reducing power of Calotropis gigantea in the synthesis of silver and gold nanoparticles. The functional groups like $\mathrm{C}-\mathrm{N}, \mathrm{C}-\mathrm{O}-\mathrm{C}, \mathrm{N}-\mathrm{H}$ amide linkages and -COO- could serve as a reducing and capping agent during the synthesis of nanoparticles [8]. The $\mathrm{O}-\mathrm{H}$ stretching which corresponds to the alcohol and phenol served as reducing agent [11].
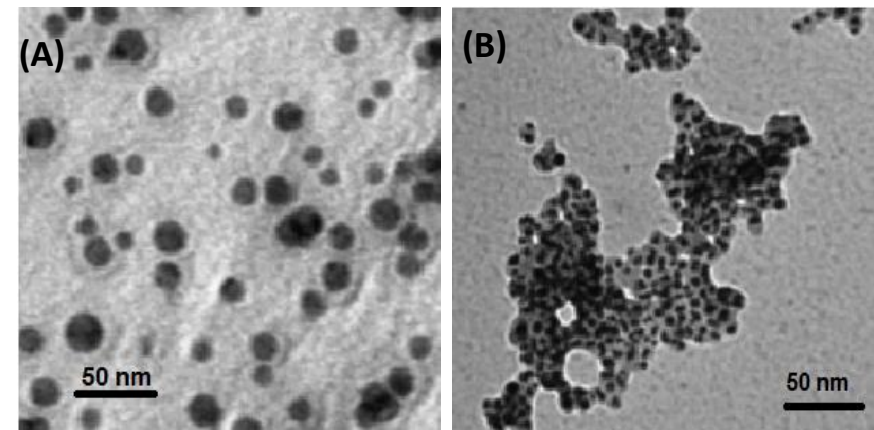

Fig. 1 TEM images of a) silver NPs and b) gold NPs derived by reduction and stabilization of Calotropis gigantean
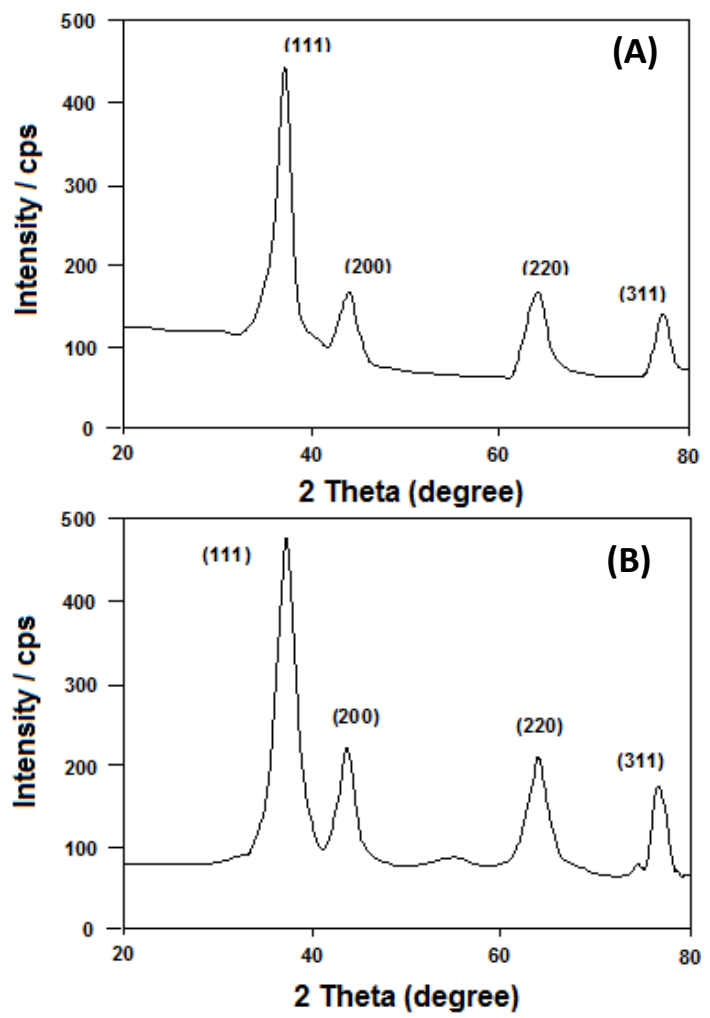

Fig. 2 XRD peaks of a) silver NPs and b) gold NPs derived by reduction and stabilization of Calotropis giganted

The size of the AgNPs were found to between 8 to $24 \mathrm{~nm}$ (Fig. 1a) with a morphology of poly-dispersed spherical particles. The XRD analysis of AgNPs showed a Bragg reflections peak at (111), (200), (220) and (311) confirming face centered cubic lattice (Fig. 2a). Zeta potential of the AgNPs was found to $-29.8 \mathrm{mV}$ (Fig. 3a). The size of the AuNPs were found to between 5 to $17 \mathrm{~nm}$ (Fig. 2b) which having a morphology of polydispersed spherical particles. The XRD analysis of AuNPs showed a Bragg reflections peak at (111), (200), (220) and (311) confirming face centered https://doi.org/10.30799/jnst.300.20060203 cubic lattice (Fig. 2b), with a zeta potential value of $-31.5 \mathrm{mV}$ (Fig. 3b). Nanoparticles which are having a zeta potential \pm 30 to \pm 40 exhibits moderate stability [12].
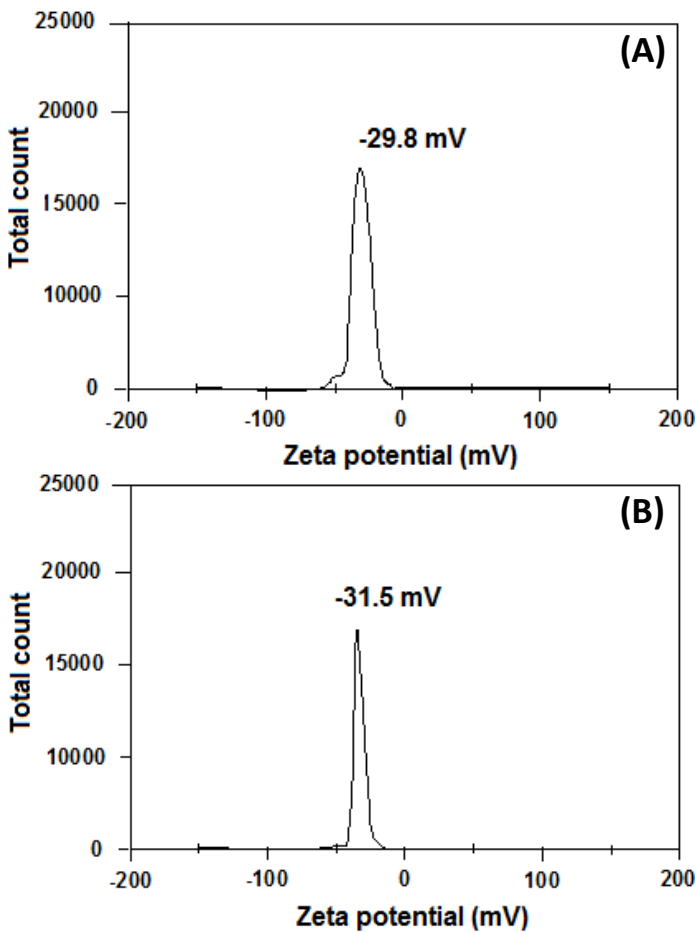

Fig. 3 Zeta potential of biosynthesised a) silver NPs and b) gold NPs

3.2 Antibacterial Activity of Silver and Gold Nanoparticles by Well Diffusion Method

The zones of inhibition due to the antimicrobial effect of silver and gold NPs were carried out at varying concentration of $5,10,20$ and $30 \mu \mathrm{L}$ by incubating for $24 \mathrm{~h}$ at $35^{\circ} \mathrm{C}$. The results showed that both silver and gold nano particles exhibited greater inhibition zone against Staphylococcus aureus (Gram positive) followed by Escherichia coli (Gram negative) bacterium (Table 1). The main reason for the variation in inhibition zone is corroborated to the cell structure [12]. The possible explanation for the antimicrobial effect due to the silver and gold nanoparticles could be reasoned due to the larger surface area which results in higher affinity towards the bacterial cell wall. The adsorption of nanoparticle on cell wall increase the membrane permeability that leads to intracellular leakage and subsequently cell death due to deactivation of enzyme and denature of DNA molecule. E. coli being gram negative bacteria has thick layer of peptidoglycan compared to $S$. aureus, thus shows a marginal increased resistance $[13,14]$.

Table 1 Antimicrobial effect of silver and gold nanoparticles in well diffusion method

\begin{tabular}{lll}
\hline Microorganism & \multicolumn{2}{l}{ Inhibition Zone (mean \pm SD) mm } \\
\cline { 2 - 3 } & AgNP’s $(10 \mu \mathrm{L})$ & AuNP’s $(20 \mu \mathrm{L})$ \\
\hline Staphylococcus aureus & $21.5( \pm 4.3)$ & $23.4( \pm 3.7)$ \\
Escherichia coli & $19.4( \pm 2.7)$ & $21.5( \pm 2.3)$ \\
\hline
\end{tabular}

3.3 Evaluation of Antimicrobial Effect of Silver and Gold Nanoparticles Impregnated on Cotton Fabric

The antibacterial property of silver nanoparticle impregnated cotton fabric against E. coli and S. aureus were evaluated by the parallel streak method by observing and measuring the bacterial growth underneath and around the cloth. The results of bioassay showed that the bacterial growth of S. aureus and E. coli was completely inhibited in the fabric treated with silver and gold nanoparticles. The mechanism of antibacterial activity of silver and gold NPs applied to fabric could be possibly due to controlled release of NPs from matrix.

\section{Conclusion}

The current investigation reveals that the aqueous flower extract of Calotropis gigantea could capable of serve as a reducing and stabilizing agent in the synthesizing silver and gold nanoparticles. The synthesized silver and gold nanoparticles resulted in a narrow size ranging between 8 
$\mathrm{nm}$ to $17 \mathrm{~nm}$ and $9 \mathrm{~nm}$ to $20 \mathrm{~nm}$ respectively. The nanocoated cotton fabric with silver and gold exhibited microbial growth inhibition, thus paving way for creating medical textiles. The current results proved that it follows the footprints of nanotechnology in judicious manner and greater benefits could be derived; thereby negative impacts on the environment could be minimized.

\section{Acknowledgment}

This research work was funded by the University Grant Commission, India under the minor research project - FRMP-6368/16 (UGC-SERO). We acknowledge UGC for funding the minor research project. We are grateful to the management of Sir Theagaraya College, Chennai and Hindustan Institute of Technology \& Science, Chennai. We also acknowledge SAIFIITM for the TEM and XRD analysis.

\section{References}

[1] D.R. Boverhof, C.M. Bramante, J.H. Butala, S.F. Clancy, M. Lafranconi, et al., Comparative assessment of nanomaterial definitions and safety evaluation considerations, Regul. Toxicol. Pharmacol. 73 (2015) 137-150.

[2] J. Santhoshkumar, S. Rajeshkumar, S. Venkat Kumar, Phyto-assisted synthesis, characterization and applications of gold nanoparticles - A review, Biochem. Biophy. Report 11 (2017) 46-57.

[3] O. Ahmadi, H.J. Malmiri, N. Jodeiri, Microwave-enhanced silver nanoparticle synthesis using chitosan biopolymer: optimization of the process conditions and evaluation of their characteristics, Green Process Synth. 7 (2018) 530-537.
[4] K. Vijayaraghavan, S.P. Kamala Nalini, N. Udaya Prakash, D. Madhankumar Biomimetric synthesis of silver nanoparticles by aqueous extract of Syzgium aromaticum, Mater. Lett. 75 (2012) 33-35.

[5] D. Ratul Kumar, S. Pragya, N. Pradip, B. Utpal, Synthesis of gold nanoparticles using aqueous extract of Calotropis procera latex, Mater. Lett. 65 (2011) 610613.

[6] U. Murad, S.A. Barkatullah Khan, M. Ibrar, S. Ullah, U. Khattak, Synthesis of silver and gold nanoparticles from leaf of Litchi chinensis and its biological activities, Asian Pac. J. Trop. Biomed. 8 (2018) 142-149.

[7] C. Rajkuberan, S. Prabukumar, G. Sathishkumar, A. Wilson, K. Ravindran, S. Sivaramakrishnan, Facile synthesis of silver nanoparticles using Euphorbia antiquorum $L$. latex extract and evaluation of their biomedical perspectives as anticancer agents, J. Saudi Chem. Soc. 21 (2017) 911-919.

[8] J. Sivakumar, C. Premkumar, P. Santhanam, N. Saraswathi, Biosynthesis of silver nanoparticles using Calotropis gigantean leaf, Afr. J. Basic Appl. Sci. 3 (2011) 265-270.

[9] K.V. Pavani, K. Gayathramma, Synthesis of silver nanoparticles using extracts of Calotropis gigantean flowers, Int. J. Res. Pharm. Nano Sci. 4 (2015) 236-240.

[10] C. Karthik, K. Anand, C.M. Moric Leecanro, K.R. Preethy, Phytosynthesis of silver nanoparticles using Calotropis gigantea flower extract and its antibacterial activity, J. Nanosci. Nanoeng. Appl. 9 (2019) 53-60.

[11] Z.A. Yusuf, A.A. Shemau, S.A. Haalima, Phytochemical analysis of the methanol leaves extract of Paullinia pinnata linn., J. Pharmaco. Phytother. 6 (2014) 1016.

[12] Y.N. Slavin, J. Asnis, U.O. Häfeli, H. Bach, Metal nanoparticles: understanding the mechanisms behind antibacterial activity, J. Nanobiotechnol. 15 (2017) 1-20.

[13] Q.L. Feng, J. Wu, G.Q. Chen, F.Z. Cui, T.N. Kim, J.O. Kim, A mechanistic study of the antibacterial effect of silver ions on Escherichia coli and Staphylococcus aureus, J. Biomed. Mater. Res. 52 (2000) 662-668.

[14] T.H. Kim, M. Kim, H.S. Park, U.S. Shin, M.S. Gong, H.W. Kim, Size dependent cellular toxicity of silver nanoparticles, J. Biomed. Mater. Res. A 100 (2012) 1033-1043. 